\title{
Characteristics of Drainage Water Quality and Loading from Paddy Field under Cyclic Irrigation and Its Management Options
}

\author{
Nobumasa Hatcho' ${ }^{1}$, Kazuyuki Kurihara ${ }^{2}$, Yutaka Matsuno ${ }^{1 *}$, Haruhiko Horino ${ }^{3}$ \\ ${ }^{1}$ Graduate School of Agriculture, Kindai University, Nara, Japan \\ ${ }^{2}$ Kohoku Land Improvement District, Shiga, Japan \\ ${ }^{3}$ Graduate School of Agriculture, Osaka Prefecture University, Osaka, Japan \\ Email: *matsuno@nara.kindai.ac.jp
}

How to cite this paper: Hatcho, N., Kurihara, K., Matsuno, Y. and Horino, $\mathrm{H}$. (2018) Characteristics of Drainage Water Quality and Loading from Paddy Field under Cyclic Irrigation and Its Management Options. Journal of Water Resource and Protection, 10, 73-84.

https://doi.org/10.4236/jwarp.2018.101005

Received: December 22, 2017

Accepted: January 26, 2018

Published: January 29, 2018

Copyright $\odot 2018$ by authors and Scientific Research Publishing Inc. This work is licensed under the Creative Commons Attribution International License (CC BY 4.0).

http://creativecommons.org/licenses/by/4.0/

\begin{abstract}
The cyclic irrigation system has been practiced in Japan for reducing pollutant outflow loadings from paddy fields. The cyclic irrigation is an irrigation method to reuse water by pumping drainage water and re-distributing it to the farmland. Quantification and assessment of the effects of the cyclic irrigation are needed to identify management options for maximizing the benefits of cyclic irrigation. The study was aimed at assessing loading characteristics from paddy field area under the cyclic irrigation and developing a model for simulating water and material flow in paddy field area that can be used as a management tool. The study was carried out in a paddy field in the Asagoi District, Oumihatiman city in Shiga Prefecture, Japan. Using the results of water quality analysis, the average net loadings of T-N and T-P were estimated for both cyclic and non-cyclic irrigation sites. The result indicates a higher nutrient absorption rate in the cyclic irrigation site than that in the non-cyclic irrigation site. The developed cyclic irrigation model showed good agreements between observed and simulated drainage volumes and nitrogen loadings. The scenario analysis by application of the model showed a potential of reducing the loading amount by increasing the cyclic irrigation ratio and reducing the amount of fertilizer application without affecting the rice yield.
\end{abstract}

\section{Keywords}

Cyclic Irrigation, Water Saving, Simulation Model, Water Balance, Material Balance, Drainage Water

\section{Introduction}

Biwa Lake is the biggest lake in Japan and an important water source for 14 mil- 
lion people in the Kinki region of the country. In the late 1960s, water pollution and eutrophication have progressed in Biwa Lake and became a serious environmental problem. Shiga Prefecture acted against this problem by enacting the Eutrophication Prevention Ordinance. As a result, the eutrophication has been controlled to some extent, but occasionally water bloom has been observed, and further improvement of Biwa Lake water quality is needed [1]. In the agricultural sector, Shiga Prefecture enacted the ordinance for promoting Environment Friendly Farming (EFF) and the direct payment system was introduced to encourage farmers to adopt EFF. In EFF, more than $50 \%$ of chemical application compared to ordinary farming should be reduced.

In addition, the introduction of cyclic irrigation system is encouraged through the national subsidy for system installation and pump operation. The cyclic irrigation pumps drainage water and reuse it as irrigation water. Originally it was intended to save irrigation water [2]; however, the function of nutrient load reduction through the reuse of wastewater receives more attention in recent years [3]. In particular, as Shiga Prefecture has the second largest share (92\%) of paddy fields in agricultural land in Japan, and it is expected that cyclic irrigation will contribute to reducing nutrient load to Biwa Lake [4]. The study was aimed at assessing loading characteristics of nitrogen and phosphorus from paddy field area under the cyclic irrigation and developing a model for simulating water and material flow in paddy field area that can be used as a management tool.

\section{Methodology}

\subsection{Study Site}

The study site is located in Asagoi Irrigation District, Omihachiman City of Shiga prefecture. It is a part of the Biwa Lake Pumping Irrigation District, which relies on its irrigation water from Biwa Lake (See Figure 1). Irrigation water is pumped from Chomeiji River at Biwa Lake Pumping Station, and distributed to 26 districts through pipelines. The diverted water is distributed to each field through a diversion gate. Drainage water from the paddy fields goes through
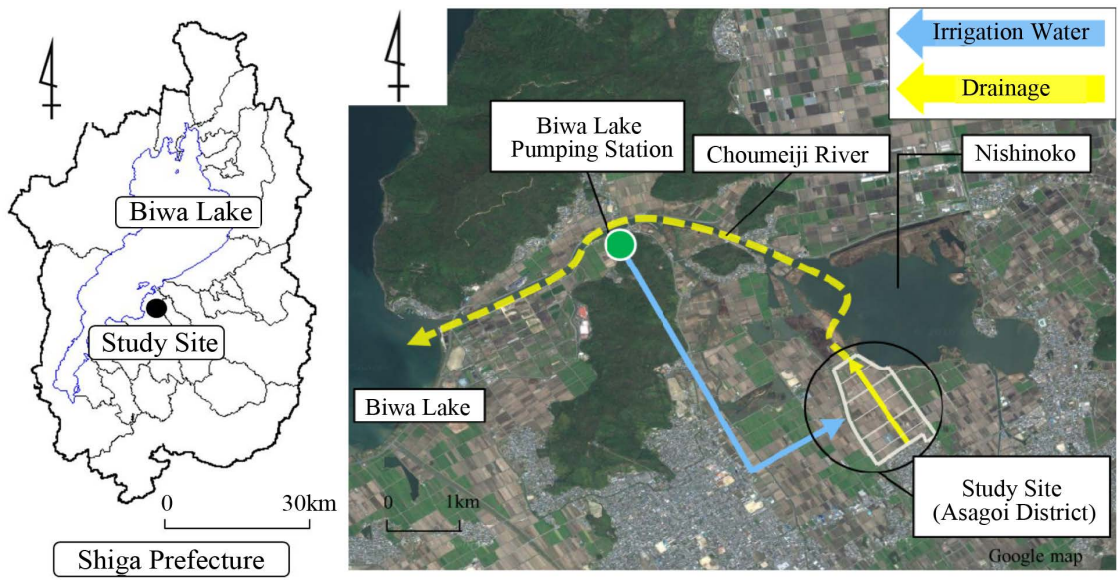

Figure 1. Location of the paddy field study site and water flow. 
branch drainage canals to the main drainage canal. The Asagoi District has a paddy field area of about 50 ha and drainage water from the district is collected in the main drainage canal that eventually flows to the Nishinoko (see Figure 2). Part of the drainage water in the main canal is pumped at point (2) and re-distributed to the farmland of 16 ha (shaded part in Figure 2). Cyclic irrigation pump is operated for 24-hours during the irrigation period, except for the period of mid-summer drainage, which is carried out from mid-June to mid-July. Farming and water management practices in this district in 2010 and 2011 are shown in Table 1. Table 2 shows farming and water management practices in 2012. Land preparation starts at the end of April or beginning of May, followed by transplanting. After transplanting paddy fields are ponded with about $6 \mathrm{~cm}$ of water until the start of the mid-summer drainage to strengthen the root growth and discharge harmful gases such as methane or hydrogen sulfide from the soil layer. After mid-summer drainage, intermittent irrigation is practiced until the

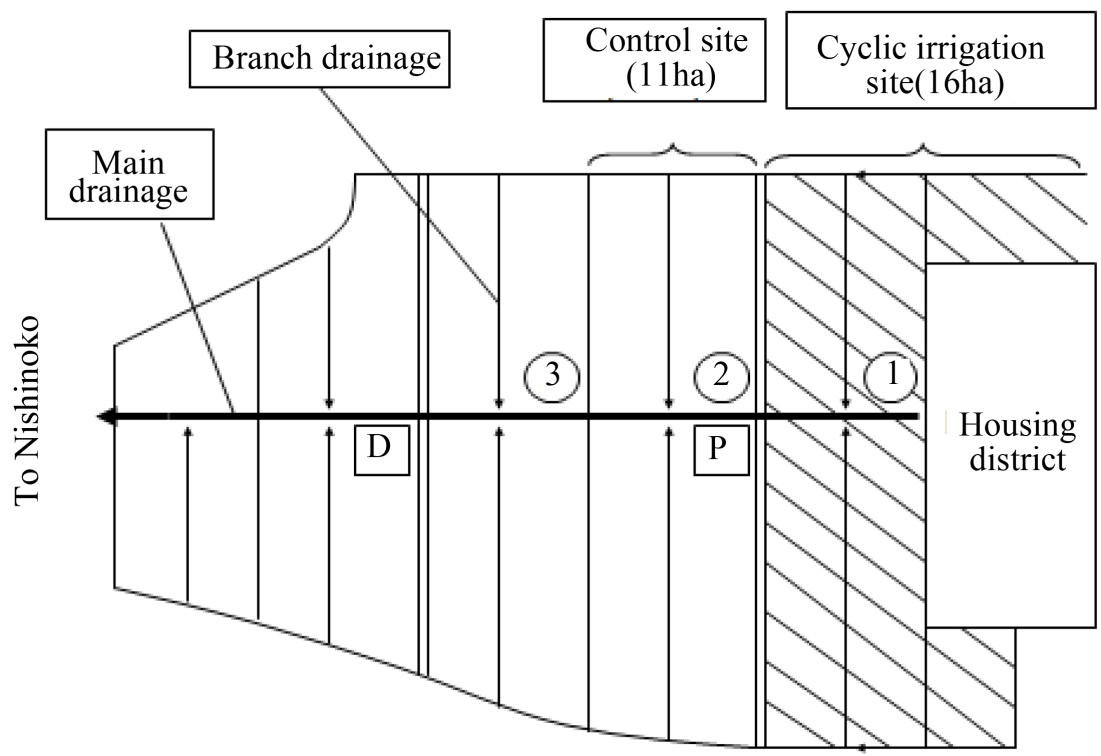

Figure 2. Schematic representation of study site and sampling points in 2010 and 2011 (1)-(3): sampling point, P: cyclic irrigation pump, D: diversion gate).

Table 1. Farming and water management practices in 2010 and 2011.

\begin{tabular}{cc}
\hline Period & Date \\
\cline { 2 - 2 } & Control site and Cyclic irrigation site \\
\hline Land preparation & $4 / 22-5 / 20$ \\
(Puddling) & $(4 / 29-5 / 6)$ \\
Transplanting & $5 / 5-5 / 15$ \\
Ordinary irrigation & $5 / 21-8 / 20$ \\
(Mid-summer drainage) & $($ about a month) \\
Intermittent irrigation & $8 / 21-9 / 23$ \\
Harvest & $9 / 6-9 / 29$
\end{tabular}


Table 2. Farming and water management practices in 2012.

\begin{tabular}{ccc}
\hline \multirow{2}{*}{ Period } & \multicolumn{2}{c}{ Date } \\
\cline { 2 - 3 } & Control site & Cyclic irrigation site \\
\hline Land preparation & $5 / 3$ & $5 / 3$ \\
Puddling & $5 / 5$ & $5 / 5$ \\
Transplanting & $5 / 10$ & $5 / 8$ \\
(Mid-summer drainage) & $(6 / 25-7 / 9)$ & $(6 / 30-7 / 12)$ \\
Heading time & $7 / 20$ & $8 / 1$ \\
Additional fertilizer & $7 / 28$ & $7 / 14$ \\
Harvest & $9 / 5$ & $9 / 6$ \\
\hline
\end{tabular}

final drainage period before harvest in September. The control site is set up next to the site for cyclic irrigation. The site covers the area of 11 ha where ordinary irrigation is practiced. In 2012, crop rotation was carried out most of the Asagoi district. So, the study plots were set up in both control site and cyclic irrigation site (Figure 3).

\subsection{Methods}

The field data were collected from April 2010 to September 2012, and the irrigation period is shown in Table 1 and Table 2. During the normal irrigation period, water samplings and flow measurements were conducted once every two weeks. During the land preparation period, samplings and measurements were carried out every day owing to the high amount of drainage loadings and variations of water quality/quantity.

The concentrations of total nitrogen (T-N) and total phosphorus (T-P) were analyzed using the Absorption Spectrophotometry method.

During the monitoring period, four sampling points were set up; three in the main drainage canal as shown in Figure 2, and one at the Biwa Lake Pumping Station. The automatic water level sensors were installed at each sampling point in main drainage canal. H-Q and L-Q curves were established to calculated daily quantity flows and loadings. The flow meter was installed at the cyclic irrigation pump ( $\mathbb{P}$ in Figure 2) to quantify the inflow of drainage water to the cyclic irrigation area. Inflow of irrigation water was recorded at the diversion gate and the Biwa Lake Pumping Station.

In 2012, three sampling points were set up in each study plots (cyclic irrigation plot and control plot); two in the drainage canal as shown in Figure 3, and one at the hydrant in each study plots. The automatic water level sensors were installed at each sampling points in the drainage canal. The triangular weirs and the automatic water level sensors were set up at hydrant in each study plots. Inflow to the paddy field is calculated with weir formula and over-flow depth at hydrant.

In this study, net loading is used to quantify the load reduction effect by cyclic irrigation with observed data of 2010 to 2012 . 


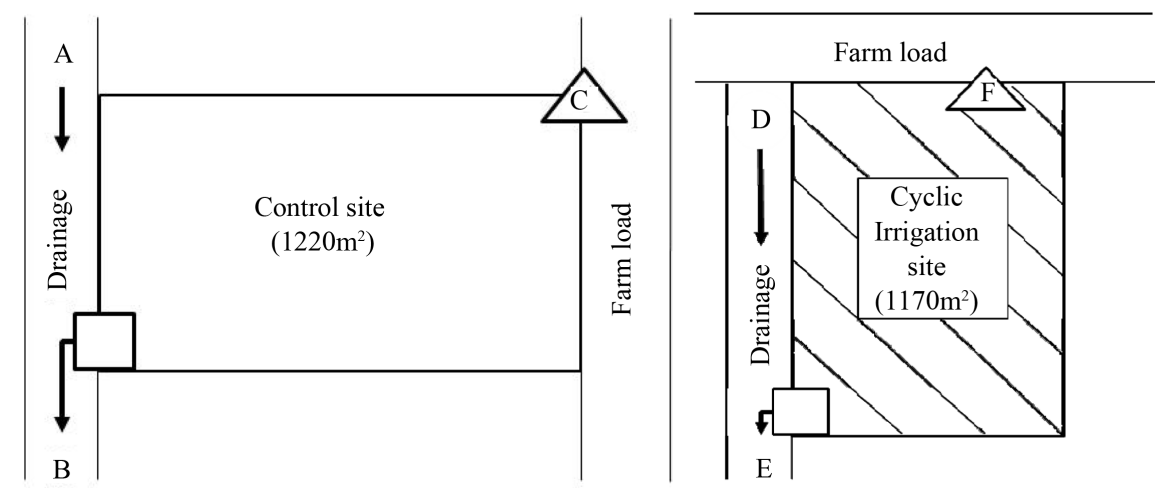

Figure 3. Schematic representation of study site and sampling points in 2012 (A-F: sampling point, $\triangle$ : Hydrant, $\square$ : Outlet).

Cyclic irrigation model was developed using System Dynamics Model (Vensim Professional). The model is composed of water balance and material balance sub-models. The model was calibrated and validated using observed and hydrological data of 2011 and 2012, and used to estimate outflow volume and nitrogen loadings from cyclic irrigation of paddy field. In addition, the model was used to conduct scenario analyses of estimating the impact of modifying farming practice of changing fertilizer application rate and cyclic irrigation rate on outflow loadings.

\subsection{Net Loadings}

The net loadings can be calculated as in equation (1):

$$
E=C_{\text {out }} Q_{\text {out }}-C_{\text {in }} Q_{\text {in }}
$$

where $C_{\text {out }}$ is the outflow concentration of T-N and T-P $\left(\mathrm{mg} \cdot \mathrm{L}^{-1}\right) . Q_{\text {out }}$ is the quantity of outflow $\left(\mathrm{m}^{3}\right) . C_{i n}$ is the inflow concentrations of T-N and T-P $\left(\mathrm{mg} \cdot \mathrm{L}^{-1}\right)$. And $Q_{i n}$ is the quantity of inflow $\left(\mathrm{m}^{3}\right) . C_{i n}$ was assumed the concentration at point (2) (Figure 2) and the Biwa Lake Pumping Station, and $Q_{\text {in }}$ is the total amount of the cyclic irrigation volume and the volume of water diverted at 4 th diversion gate. In the control site, $C_{i n}$ was assumed the concentration of Biwa lake water, $Q_{i n}$ is the diverted volume of water at 4 th diversion gate, and $C_{\text {out }} Q_{\text {out }}$ is the difference of loadings between point (3) and point (2). In 2012, $C_{i n}$ was assumed the concentration at point $F$ (Figure 3 ) and $Q_{i n}$ is the amount of irrigation water, and $C_{\text {out }} Q_{\text {out }}$ is the difference of loadings between point $E$ and point $D$ in the cyclic irrigation site. In the control site, $C_{i n}$ is the concentration at point $C$ (Figure 3 ) and $Q_{i n}$ is the amount of irrigation water, and $C_{\text {out }} Q_{\text {out }}$ is the difference of loadings between point $B$ and point $A$. The net loadings for both the cyclic irrigation and the control sites were calculated for the land preparation period and the normal irrigation period.

\subsection{Cyclic Irrigation Model}

\subsubsection{Water Balance Sub-Model}

In the water balance sub-model, the inflow to the paddy field is composed of ir- 
rigation water and precipitation, and the outflow is composed of infiltration, evapotranspiration and surface runoff [5] [6]. The irrigation water in the cyclic irrigation site is represented as in Equation (2):

$$
Q_{i n}=Q_{i r r}+Q_{c y c l i c}
$$

where $Q_{i r r}$ is the volume of water diverted at 4 th diversion gate $\left(\mathrm{m}^{3} \cdot \mathrm{ha}^{-1}\right)$, and $Q_{\text {cyclic }}$ is the total amount of the cyclic irrigation water. The water balance in the paddy field is represented as in Equation (3):

$$
\frac{\mathrm{d} P A D}{\mathrm{~d} t}=Q_{\text {in }}+P-Q_{\text {out }}-I-E
$$

where $P A D$ is ponded water volume $\left(\mathrm{m}^{3} \cdot \mathrm{ha}^{-1}\right), Q_{\text {in }}$ is irrigation water volume $\left(\mathrm{m}^{3} \cdot \mathrm{ha}^{-1}\right), P$ is precipitation $\left(\mathrm{m}^{3} \cdot \mathrm{ha}^{-1}\right), Q_{\text {out }}$ is surface runoff $\left(\mathrm{m}^{3} \cdot \mathrm{ha}^{-1}\right), I$ is infiltration $\left(\mathrm{m}^{3} \cdot \mathrm{ha}^{-1}\right)$ and $E$ is evapotranspiration $\left(\mathrm{m}^{3} \cdot \mathrm{ha}^{-1}\right)$. Inflow of irrigation water is recorded at the diversion gate and the Biwa Lake Pumping Station. Precipitation data was obtained from the Hikone meteorological station. Evapotranspiration was calculated by the Penman equation.

Weir formula is used to calculate surface runoff $\left(Q_{\text {out }}\right)$ from the paddy field:

$$
Q_{\text {out }}=C \times W \times(H-d) \sqrt{2 \times g \times(H-d)} \times 86400
$$

where $C$ is flow coefficient, $W$ is weir width (m), $H$ is ponded depth (m), $d$ is weir height $(\mathrm{m})$ and $g$ is gravitational acceleration $\left(\mathrm{m} \cdot \mathrm{s}^{-2}\right)$.

The ponded water depth within the paddy field is usually dependent on the height of outlet gate in the plot, which is controlled by farmers according to the rice growth stages. To account for the variation of water management practices by planting schedule, weir height is set as a variable parameter. Table 3 shows input parameters of the water balance sub-model.

\subsubsection{Material Balance Sub-Model}

In the material balance sub-model, inflow loadings are the sum of irrigation water loading, precipitation loading and loading from fertilizer application. Outflow loadings are calculated by discharges through infiltration, and surface runoff, denitrification, and crop absorption. The basic concept of the material balance sub-model is similar to the models applied by [3] [7] and [8].

The irrigation water loadings in the cyclic irrigation site is represented as in Equation (5):

$$
L_{\text {in }}=Q_{\text {irr }} \times C_{\text {irr }}+Q_{\text {cyclic }} \times C_{\text {cyclic }}
$$

Table 3. Parameters in the water balance sub-model.

\begin{tabular}{cccc}
\hline Item & Unit & value & Remark \\
\hline Flow coefficient & & 2.21 & Calibration \\
Weir width & $\mathrm{m}$ & 0.3 & Field data \\
Weir height & $\mathrm{m}$ & 0.06 & Irrigation period \\
& & 0 & (except for the period of mid-summer drainage) \\
& & & Mid-summer drainage \\
\hline
\end{tabular}


where $L_{\text {in }}$ is irrigation water loadings $\left(\mathrm{kg} \cdot \mathrm{day}^{-1} \cdot \mathrm{ha}^{-1}\right), C_{\text {irr }}$ is the concentration of water diverted at 4 th diversion gate $\left(\mathrm{kg} \cdot \mathrm{m}^{-3}\right)$, and $C_{\text {cyclic }}$ is the concentration of the cyclic irrigation water $\left(\mathrm{kg} \cdot \mathrm{m}^{-3}\right)$. The nitrogen balance in the paddy is represented as in Equations (6), (7) and (8)

$$
\begin{aligned}
\frac{\mathrm{d} L_{p a d}}{\mathrm{~d} t}=L_{\text {in }}+P \times C_{\text {pre }} & +\alpha \times L_{\text {fer }}-\left(I+Q_{\text {out }}\right) \times C_{p a d}-a_{0} \times C_{p a d}-F \\
\frac{\mathrm{d} L_{\text {fer }}}{\mathrm{d} t} & =F E R-\alpha \times L_{\text {fer }} \\
a_{0} & =a \times T_{W}^{2}+b
\end{aligned}
$$

where $L_{p a d}$ is amount of nitrogen in the paddy $\left(\mathrm{kg} \cdot \mathrm{day}^{-1} \cdot \mathrm{ha}^{-1}\right), C_{p r e}$ is nitrogen concentration in rain $\left(\mathrm{kg} \cdot \mathrm{m}^{-3}\right), \alpha$ is leaching rate $\left(1 \mathrm{day}^{-1}\right), L_{\text {fer }}$ is residual fertilizer in the paddy $\left(\mathrm{kg} \cdot \mathrm{ha}^{-1}\right)$, FER is amount of fertilizer applied $\left(\mathrm{kg} \cdot\right.$ day $\left.^{-1} \cdot \mathrm{ha}^{-1}\right), \quad a_{0}$ is denitrification speed $\left(\mathrm{m} \cdot \mathrm{day}^{-1}\right), C_{p a d}$ is concentration of nitrogen in ponded water $\left(\mathrm{kg} \cdot \mathrm{m}^{-3}\right), F$ is nitrogen absorption rate by crops $\left(\mathrm{kg} \cdot \mathrm{day}^{-1} \cdot \mathrm{ha}^{-1}\right), T_{w}$ is water temperature $\left(10^{\circ} \mathrm{C} \leq T_{W} \leq 40^{\circ} \mathrm{C}\right)$, and both $a$ and $b$ are nitrogen removal coefficients.

Nitrogen absorption by crops is calculated by accumulated temperature using a logistics curve, so it is only variable by temperature changes. Table 4 shows input parameters in the material balance sub-model.

\section{Results and Discussion}

\subsection{Net Loadings}

Net loadings were calculated using the Equation (1) for the cyclic irrigation system and the control site during the periods of the land preparation and the normal irrigation periods. The result is shown in Table 5. The standard deviation is shown within parenthesis.

The average net loadings of T-N and T-P in the cyclic irrigation site were negative, while they were positive in the control site. Negative net loadings suggest that nutrients are accumulated or absorbed in the cyclic irrigation site. Positive net loadings in the control site suggest that applied nutrient (chemical fertilizer) was leached out of the field into the drainage canal.

Comparison of the land preparation period and normal irrigation period in the control site showed that net loadings during the land preparation period

Table 4. Parameters in the material balance sub-model.

\begin{tabular}{cccc}
\hline Item & Unit & Value & Remark \\
\hline Leaching rate $(a)$ & 1 day $^{-1}$ & 0.043 & Calibration \\
Rain concentration $\left(C_{p r e}\right)$ & $\mathrm{kg} \cdot \mathrm{m}^{-3}$ & 1.05 & Reference [9] \\
Crops absorption $(F)$ & $\mathrm{kg} \cdot \mathrm{day}^{-1} \cdot \mathrm{ha}^{-1}$ & $0-1$ & Reference [10] \\
Nitrogen removal coefficient $(a)$ & & $1.1 \times 10^{-5}$ & Reference [11] \\
Nitrogen removal coefficient $(b)$ & & $0.5 \times 10^{-2}$ & Reference [11] \\
\hline
\end{tabular}


Table 5. Average net loadings $\left(\mathrm{kg} \cdot \mathrm{day}^{-1} \cdot \mathrm{ha}^{-1}\right)$ in the cyclic irrigation site and control site.

\begin{tabular}{ccccc}
\hline & \multicolumn{2}{c}{ Cyclic irrigation site } & \multicolumn{2}{c}{ Control site } \\
\hline & T-N & T-P & T-N & T-P \\
\hline Land Preparation Period & -0.95 & -0.19 & 0.48 & 0.24 \\
(STD) & $(0.53)$ & $(0.15)$ & $(0.49)$ & $(0.48)$ \\
Normal Irrigation Period & -0.46 & $(-0.08)$ & 0.18 & 0.00 \\
(STD) & $(0.28)$ & $(0.06)$ & $(0.33)$ & $(0.27)$ \\
\hline
\end{tabular}

were higher than during the normal irrigation period, while the opposite was true in the cyclic irrigation site. In the control site, outflow loadings were higher than inflow loadings due to the outflow of fertilizer that was not absorbed during the land preparation period, which led to higher net loadings during the land preparation period. In the cyclic irrigation site, inflow loadings became larger than outflow loadings due to the reuse of drainage water, and the loadings during the land preparation period were higher than those during the normal irrigation period. Negative net loadings of the cyclic irrigation site, particularly during the land preparation period, suggest that cyclic irrigation can reduce the outflow loadings, contributing to the control of eutrophication in the Nishinoko and the Lake Biwa basin.

\subsection{Calibration and Validation of the Cyclic Irrigation Model}

\subsubsection{Calibration and Validation of the Water Balance Sub-Model}

The water balance sub-model was calibrated by comparing the observed and simulated drainage value of 2011 (Figure 4). As a result, simulated and observed values were in reasonably good agreement with the least square equation of $\mathrm{Y}=$ $0.92 \mathrm{X}$ with $\mathrm{R}^{2}=0.71$ where $\mathrm{X}$ and $\mathrm{Y}$ are simulated and observed values, respectively. The average volumes of drainage for observed and simulated values were $9.7 \mathrm{~mm} \cdot \mathrm{day}^{-1}$ and $10.4 \mathrm{~mm} \cdot$ day $^{-1}$, respectively, with the difference of $8 \%$ (Table $5)$.

The water balance sub-model was validated by comparing the observed and simulated drainage values (Figure 5). Some observed data was missing due to the trouble of the automatic level sensors at sampling point $\mathrm{D}$ in the drainage canal. Simulated and observed values had relatively high correlation by the least square equation of $\mathrm{Y}=0.81 \mathrm{X}$ with $\mathrm{R}^{2}=0.51$. The average volumes of drainage for observed and simulated values were $11.1 \mathrm{~mm} \cdot \mathrm{day}^{-1}$ and $9.8 \mathrm{~mm} \cdot \mathrm{day}^{-1}$, respectively, with the difference of $12 \%$ (Table 6). The application and the model-fitness-test indicated that the simulation results reasonably matched the observed data.

\subsubsection{Calibration and Validation of the Material Balance Sub-Model}

The material balance sub-model was calibrated by comparing the outflow loadings of observed and simulated data (Figure 6). The model and input parameters were so set that high correlation could be obtained between simulated and 


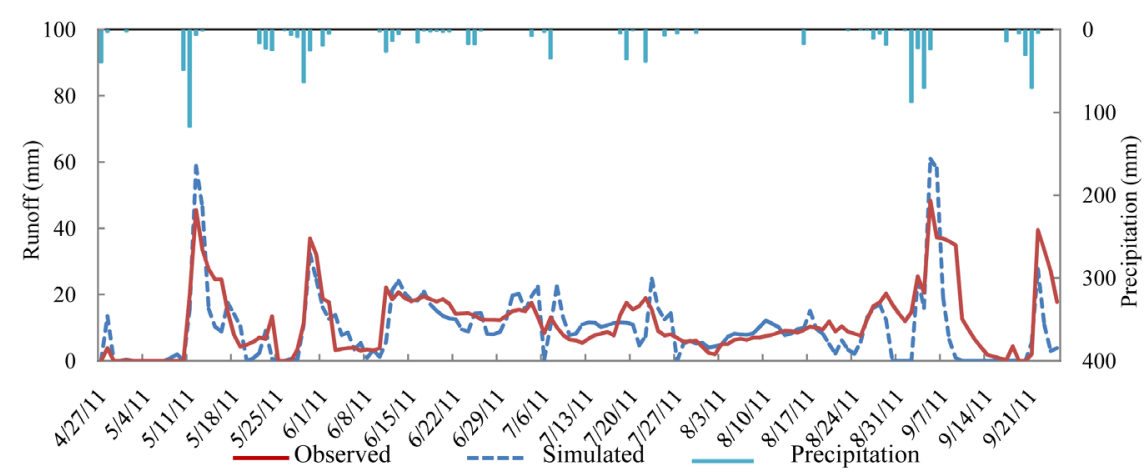

Figure 4. Drainage volumes of observed and simulated values for calibration period.

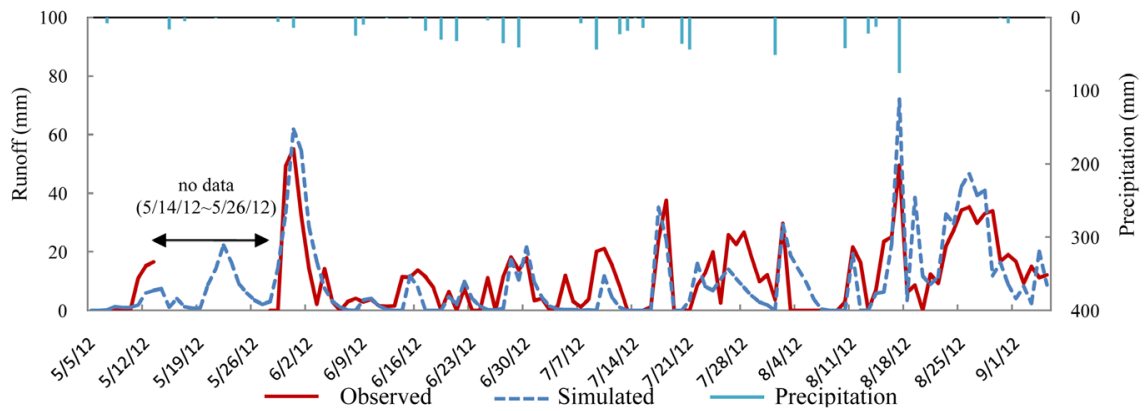

Figure 5. Drainage volumes of observed and simulated values for validation period (2012).

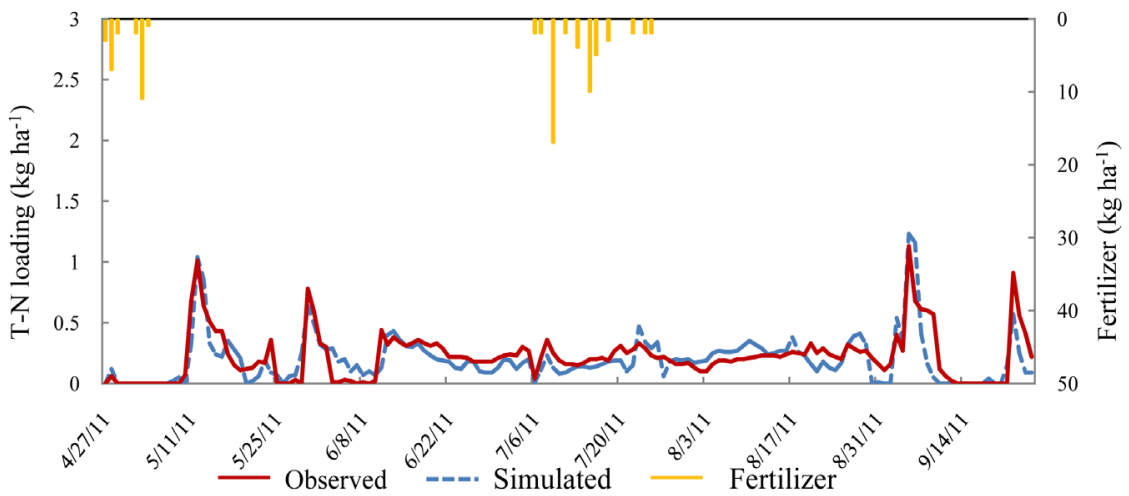

Figure 6. Outflow loadings of observed and simulated values for calibration period.

Table 6. Reproducibility of the water balance sub-model.

\begin{tabular}{ccccc}
\hline & Observed & Simulated & Difference & \\
\hline Calibration & $9.7 \mathrm{~mm} \cdot$ day $^{-1}$ & $10.4 \mathrm{~mm} \cdot$ day $^{-1}$ & $8 \%$ & $\mathrm{Y}=0.92 \mathrm{X} \mathrm{R}^{2}=0.71$ \\
Validation & $11.1^{\star} \mathrm{mm} \cdot \mathrm{day}^{-1}$ & $9.8 \mathrm{~mm} \cdot \mathrm{day}^{-1}$ & $12 \%$ & $\mathrm{Y}=0.81 \mathrm{X} \mathrm{R}^{2}=0.51$ \\
\hline
\end{tabular}

(X: Simulated value, Y: Observed value).

observed values. The least square equation of $\mathrm{Y}=0.99 \mathrm{X}$ was obtained with $\mathrm{R}^{2}=$ 0.71 where $\mathrm{X}$ is the simulated value and $\mathrm{Y}$ is the observed value. The average outflow loadings of observed and simulated values were $0.16 \mathrm{~kg} \cdot \mathrm{day}^{-1} \cdot \mathrm{ha}^{-1}$ and 
$0.18 \mathrm{~kg} \cdot \mathrm{day}^{-1} \cdot \mathrm{ha}^{-1}$, respectively and the difference between them was $12 \%$ (Table 6). The T-N loading did not increase during the land preparation period and the additional fertilizing period. This is because water management was practiced in such a way to minimize the outflow from the paddy field (for saving fertilizer and avoiding water pollution).

The material balance sub-model was validated by comparing the observed and simulated outflow loadings of 2012 (Figure 7). As such, simulated and observed values had relatively high correlation by the least square equation of $\mathrm{Y}=0.91 \mathrm{X}$ with $\mathrm{R}^{2}=0.70$. The average outflow loadings of observed and simulated values were $0.24 \mathrm{~kg} \cdot \mathrm{day}^{-1} \cdot \mathrm{ha}^{-1}$ and $0.21 \mathrm{~kg} \cdot \mathrm{day}^{-1} \cdot \mathrm{ha}^{-1}$, respectively, with the difference of $12 \%$ (Table 7). The application and the model-fitness-test indicated that the simulation results reasonably matched the observed data.

\subsection{Scenario Analysis}

\subsubsection{Effect of Cyclic Irrigation Ratio on Outflow Loading}

Effects of changing cyclic irrigation ratio on nitrogen loadings were tested by using the cyclic irrigation model. Table 7 shows relationships between the cyclic irrigation ratio and $\mathrm{T}-\mathrm{N}$ load reduction rate. The result shows that with the rise of cyclic irrigation ratio, outflow loadings decreases. Average load reduction rate of cyclic irrigation is calculated to be about $8.6 \%$ for every $10 \%$ increase of cyclic irrigation ratio (Table 8 ).

\subsubsection{Effect of Fertilizer Application Rate on Outflow Loading}

The effects of reducing fertilizer application by $10 \%, 20 \%, 30 \%, 40 \%$ and $50 \%$ from the ordinary farming practice on nitrogen loadings were simulated by using the cyclic irrigation model. Table 8 shows the relationships between the reduction rate of fertilizer and $\mathrm{T}-\mathrm{N}$ load reduction rate. The result shows that as fertilizer application rate is reduced, the outflow loadings decreased. Average load reduction rate of cyclic irrigation is estimated to be $8.2 \%$ for every $10 \%$ decrease of fertilizer application rate (Table 9).

\section{Conclusions}

In this study, the effects of the cyclic irrigation on the discharge of nutrients from paddy field were analyzed by using the field observed data and developing

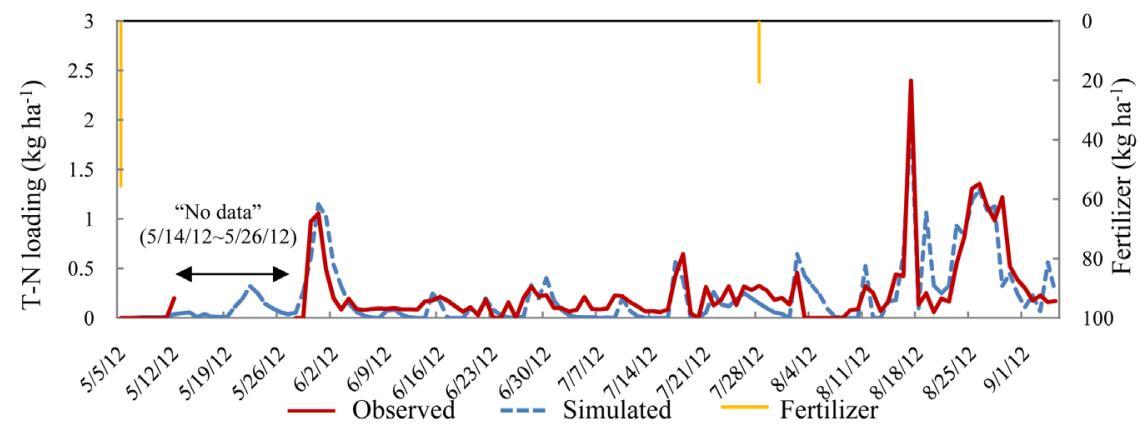

Figure 7. Outflow loadings of observed and simulated values for validation period. 
Table 7. Reproducibility of the material balance sub-model.

\begin{tabular}{ccccc}
\hline \multicolumn{3}{c}{ Observed } & Simulated & Difference \\
\hline Calibration & $0.16 \mathrm{~kg} \cdot \mathrm{day}^{-1} \cdot \mathrm{ha}^{-1}$ & $0.18 \mathrm{~kg} \cdot \mathrm{day}^{-1} \cdot \mathrm{ha}^{-1}$ & $12 \%$ & $\mathrm{Y}=0.99 \mathrm{X} \mathrm{R}^{2}=0.71$ \\
Validation & $0.24^{\star} \mathrm{kg} \cdot \mathrm{day}^{-1} \cdot \mathrm{ha}^{-1}$ & $0.21 \mathrm{~kg} \cdot \mathrm{day}^{-1} \cdot \mathrm{ha}^{-1}$ & $12 \%$ & $\mathrm{Y}=0.91 \mathrm{X} \mathrm{R}^{2}=0.70^{\star}$ \\
\hline
\end{tabular}

(X: Simulated value, Y: Observed value).

Table 8. Effect of cyclic irrigation ratio (\%) on T-N load reduction rate (\%).

\begin{tabular}{cccccccccc}
\hline Cyclic irrigation ratio (\%) & 0 & 10 & 20 & 30 & 40 & 50 & 60 & 70 & 80 \\
\hline T-N load reduction rate (\%) & 0 & 8.2 & 16.5 & 24.9 & 33.4 & 42.1 & 50.9 & 60.0 & 69.2 \\
\hline
\end{tabular}

Table 9. Effect of reduction rate of fertilizer (\%) on T-N load reduction rate (\%).

\begin{tabular}{ccccccc}
\hline Reduction rate of fertilizer (\%) & 0 & 10 & 20 & 30 & 40 & 50 \\
\hline T-N load reduction rate (\%) & 0 & 8.2 & 16.4 & 24.6 & 32.8 & 40.9 \\
\hline
\end{tabular}

the simulation model. The analyses on the net loadings suggest that, in the cyclic irrigation system, nutrients (T-N and T-P) were absorbed and lower loadings of nutrients were recorded compared to the control site where the ordinary irrigation is practiced.

The developed cyclic irrigation model was calibrated and validated by using the observed values of drainage discharge volumes and nitrogen loadings. The model was then applied to conduct scenario analyses to examine the effects of cyclic irrigation ratio and fertilizer application rate on outflow loadings. The results showed the potential of reducing the loadings by increasing the cyclic irrigation ratio and reducing the amount of fertilizer application.

\section{Acknowledgements}

We are deeply grateful to the Biwa Pumping Land Improvement District and farmers in the Asagoi district for the support and cooperation for conducting this study.

\section{References}

[1] Sato, Y., Okubo, T., Okamoto, T. and Uehara, H. (2009) Biwako ryuuiki kannri sisutemu ni kannsuru seisaku kadai kennkyuu (In Japanese). Lake Biwa Environmental Research Institute, 6, 31-45.

[2] Van, T.T.H. (2017) Water Saving through Reuse of Return Flow in Paddy Fields. In: Liniger, H., et al., Eds., Making Sense of Research for Sustainable Land Management. Centre for Development and Environment (CDE), University of Bern, Switzerland and Helmholtz-Centre for Environmental Research GmbH-UFZ, Leipzig.

[3] Hama, T., Nakamura, K., Kawashima, S. and Mitsuno, T. (2008) Effect of Cyclic Irrigation on Reduction of Net Effluent Loadings of Nitrogen and Phosphorus during Sunny Days in Irrigation Period after Puddling Season. Journal of the Agricultural Engineering Society, Japan, 76, 419-425.

[4] Aiba, N., Obayasi, H., Hasukawa, H. and Yamada, Y. (2011) Runoff Load Reduction 
by Circulatory Irrigation in Paddy Field Region. Bull. Shiga. Pref. Agric. Tech. Promo. Cent, 50, 37-40.

[5] Wu, R.S., Sue, W.R., Chien, C.B., Chen, C.H., Chang, J.S. and Lin, K.M. (2001) A Simulation Model for Investigating the Effects of Rice Paddy Fields on the Runoff System. Mathematical and Computer Modeling, 33, 649-658. https://doi.org/10.1016/S0895-7177(00)00269-7

[6] Andiego, G., Waseem, M., Usman, M. and Mani, N. (2018) The Influence of Rain Gauge Network Density on the Performance of a Hydrological Model. Computational Water, Energy, and Environmental Engineering, 7, 27-50. https://doi.org/10.4236/cweee.2018.81002

[7] Kim, S.M., Im, S.J., Park, S.W., Lee, J.J., Benham, B.L. and Jang, T.I. (2008) Assessment of Wastewater Reuse Effects on Nutrient Loads from Paddy Field Using Field-Scale Water Quality Model. Environmental Modeling \& Assessment, 13, 305-313. https://doi.org/10.1007/s10666-007-9093-7

[8] Jeon, J.H., Yoon, C.G., Ham, J.H. and Jung, K.W. (2005) Model Development for Surface Drainage Loading Estimates from Paddy Rice Fields. Paddy and Water Environment, 3, 93-101. https://doi.org/10.1007/s10333-005-0007-5

[9] Kunimatsu, T. and Sudo, M. (1994) Taikikoukabutu niyoru chitso, rinn no kyoukyu to sonohenndou (In Japanese). Society of Environmental Conservation Engineering, 23, 710-713. https://doi.org/10.5956/jriet.23.710

[10] Sato, K. and Takahashi, T. (1998) Analysis of the Relation between Soil Nitrogen Absorption by Paddy Rice and Accumulated Temperature Using a Logistics Curve. Japanese Society of Soil Science and Plant Nutrition, 69, 29-37.

[11] Tabuchi, T. (2006) To Develop the Theory for Nitrate Removal in Wetland. Journal of the Agricultural Engineering Society, Japan, 74, 7-10. 